\title{
The Study of Knowledge Innovation Based on Enterprise Knowledge Ecosystem
}

\author{
Mingkui Huo ${ }^{1}$ \\ ${ }^{1}$ School of Economics and Management, Changchun University of Science and Technology, Changchun 130022, \\ China \\ Correspondence: Mingkui Huo, School of Economics and Management, Changchun University of Science and \\ Technology, Changchun 130022, China. E-mail: huomingkui@163.com
}

Received: January 17, 2013

Accepted: January 31, 2013

Online Published: February 2, 2013

doi:10.5430/bmr.v2n1p69

URL: http://dx.doi.org/10.5430/bmr.v2n1p69

\begin{abstract}
Knowledge Innovation is the ultimate driving force for enterprise development. Based on the principles of ecology, this article builds a model of Enterprise Knowledge Ecosystem, and based on the point of Enterprise Knowledge Ecosystem, does research on knowledge innovation process, aimed for providing a new thinking of knowledge innovation.
\end{abstract}

Keywords: Ecosystem, Enterprise knowledge ecosystem, Knowledge innovation

\section{Introduction}

The technology revolution and the globalization promoted a new era of knowledge-based economy. To meet the challenges of the times, organizations of $21 \mathrm{c}$ are faced an inevitable choice with three kinds of complex changes: First, innovation of the operation and the market has become more important; Second, more attentions on information; Third, more attentions on knowledge.

Due to the rapid development of information technology, information and technology are becoming the most important strategic resources, and knowledge industry are becoming the main body of economy, knowledge innovation has become the main enterprise innovation. To increase awareness of the business and to maintain a competitive advantage, knowledge innovation is necessary. In recent years, the research of knowledge innovation has become a hot topic in academic, and all kinds of theory of knowledge innovation have been introduced (Chen, Yewu, 2000), but less are based on the ecological view. Based on previous research, this article studied the knowledge innovation based on the point of ecosystem.

\section{The innovative nature of the ecosystem}

Ecosystem has many creatures, and the biological environment conducts continuous cycle of materials and energy flow (Sun Ruyong, 1992). In spaces between species, in particular between species and the environment interacting all the time: plants absorb energy from the external environment, animals obtain energy from plants, micro-organisms obtain energy through the decomposition of animals and plants, and the energy chain is linked into a ring at last. During the processes of energy flow, in addition to this collaboration, there is also competition. Competition and cooperation jointly promote the evolution of species and the growth of ecosystems.

When the environment changes or resources become limited, ecosystems and habitats failed to develop. They will do everything possible to find out. Despite the repeated defeats, there is always a chance to find survivors in good condition. Whenever, the ecosystem approach would be to "record" and "save" them. Through natural selection, biological organ leaves the DNA into existence in the code; more complex species will be recorded in the memory of the individual or culture (such as human), so, good character can be preserved and passed from generation to generation (Tachi Kiuchi, Bill Shireman. 2003).

In general, the ecosystem is innovated through two ways: continuous improvement and breakthrough. First, breakthrough innovation can continue to create a model to copy products; second, continuous improvement is adjusted to design product and adapted to the local environment, and also make continued evolution and variation of a breakthrough. For example: reproductive cells are used in two ways: mitosis have suddenly stopped; maturity is a new type of split. There are two planets that have evolved: there is a sudden geological disasters triggered by the sudden change, such as volcanic eruptions and collided with the planet; day-to-day are changed. 


\section{Enterprise Knowledge Ecosystem}

Ecological theory has become a solid scientific basis in mature, so many points can be used to explain the system of dynamic interaction. In the ecological point, there is a specific scope of the system that can be regarded as an ecosystem. Systems and components of the system have similar mechanism of action. As early as the mid-70s of the last century, scholars have tried to explore the ecological theory of organizational management, and established Organization Ecology (Xie Wangdan, 2004). In 1997, the Thomas Davenport put forward "Information Ecology" (T H Davenport, L Prusak, 1997), and introduced the concept of ecological information management. He explored how the organization played a role in better organizing information management.

As is biological system, in a certain region, there is no Knowledge Individuals (knowledge individual means individuals, groups or companies who have a high level of knowledge to solve the problem and to provide specialized knowledge) who can survived separately. In the enterprise, each of the main body of knowledge, directly or indirectly relies on the others and the surroundings.

We have this knowledge interaction system called knowledge ecosystem. According to its coverage, there are macro-and micro-ecology: in macro knowledge ecosystem, individual enterprises are the main unit, and the social environment is the background. In this paper, the enterprise knowledge ecosystem is the typical micro knowledge ecosystem.

\subsection{The Characters of EKE}

Enterprise Knowledge Ecosystem originates from ecosystem, and will inevitably have similar characteristics to ecosystem:

(1) Openness. As ecosystem is, Enterprise Knowledge Ecosystem is also an open up system, which constantly interacts with the world, especially with other Enterprise Knowledge Ecosystems for knowledge exchange. The internal knowledge is limited. If there is no knowledge outside of the world to stimulate, Enterprise Knowledge Ecosystem evolves slowly and inefficiently, it is openness that create a colorful system

(2) Dynamic. Enterprise Knowledge Ecosystem is an organic whole, it is always in constant movement, mainly in the knowledge interaction between systems (this process is also called the role of the system), in order to adapt to the changes in the external environment with gradual adjustment as well as its ground-breaking change that took place.

(3)Competitive. In the ecosystem, knowledge resources are scarce everywhere, the scarcity stimulates competition, but also stimulates the individual knowledge of the continued feedback, learning and adaptation. Individual evolution in such environment forms a stable knowledge interacting net.

(4) Evolution. Through the absorption of external knowledge, dynamic interaction and competition, Enterprise Knowledge Ecosystem evolved and individuals grow.

\subsection{The model design of EKE}

As a whole, there is continuous knowledge exchange between knowledge units and surroundings in EKE. Knowledge, Knowledge individuals and the surrounding( include KM technology , corporate culture, organizational structure, knowledge strategy, infrastructure) formed the artificial ecosystem together.

The author designed the model of EKE from the perspective of ecosystem and knowledge management, as follows (graph 1):

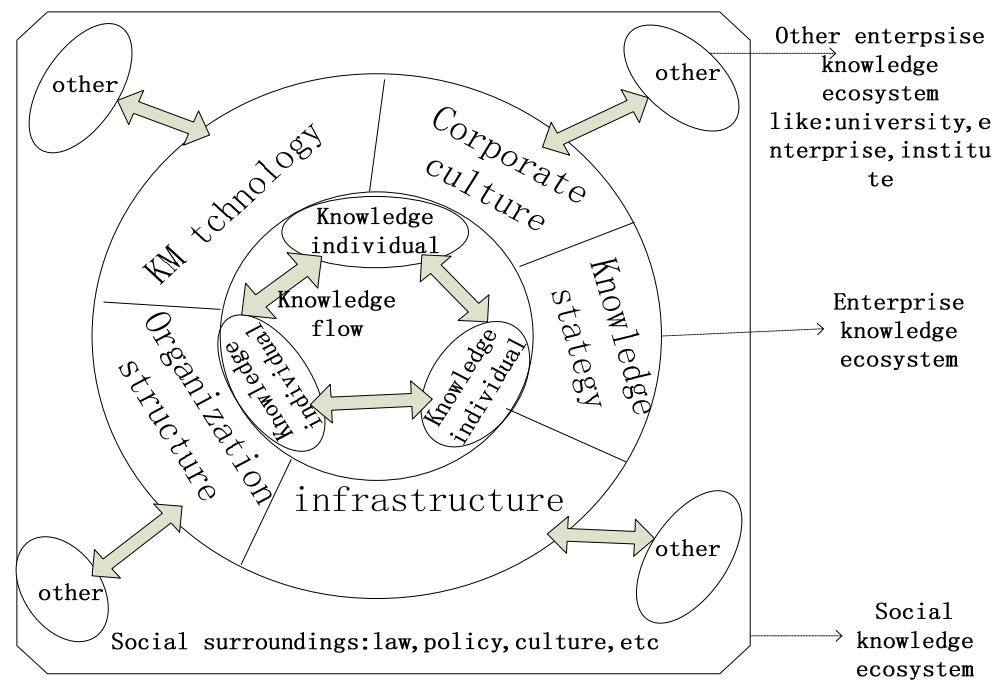

Graph 1. Model of Enterprise Knowledge Ecosystem 
From the model it can be seen that it is the non-stop knowledge interaction between knowledge individuals and surrounding that promote the growth of ecosystem.

In fact, enterprise knowledge ecosystem is not a maverick concept, Japan Kitaro Nishida scholars put forward the "Ba" (Von Krogh Georg. 1998) concept can be seen as a model of knowledge ecosystem. Enterprise knowledge ecosystem is a new concept for business and knowledge management. The idea concerns the survival of the enterprise knowledge in the ecological environment, cites ecological thinking more flexible and studies the complexity of structure and knowledge management to seek more efficient corporate structure and system application knowledge and enhance their knowledge management and knowledge innovation.

\subsection{The Evolution of EKE}

The process of nature ecosystem's succession is a cycle: from the beginning of the day of the birth of the ecosystem, it is necessary to continue to grow and improve themselves in order to achieve better development, until one day face a devastating cycle of destruction and re-start. However, because organisms and genetic variation, the new ecosystem from the beginning stands on top of the original ecosystem.

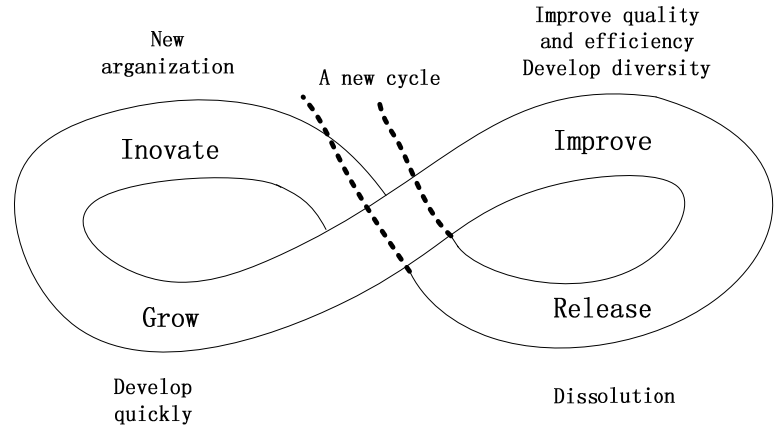

Graph 2. The nonstop cycle of EKE's innovation

The development of EKE is a very similar process with nature: dramatic changes in the business environment and the rapid updating of technical standards for enterprises. Individual knowledge has a selection pressure, only by the rising and innovation it can remain competitive advantages. Such knowledge innovation can be divided into continuous improvement and breakthrough innovation. There are two ways: a breakthrough innovation brought about a new collaboration - the collaboration brought more powerful capability of past; while continuous improvement creates a different part of the composition of the new one, the whole has ability to break through.

This article subdivides the two ways into innovation, growth, improvement and the release of four stages of a cycle. Brought about a breakthrough innovation, and continuous replicate through the promotion of growth. When growth reached the limits of time and led to continuous improvement in order to start a new round of innovation and development.

The first stage: Innovate. Maybe in the stage of the birth, through the integration process, individual knowledge, as a whole, is innovated; in particular, the permutation and combination had a synergistic effect.

The second stage: Grow. The stage is completed through replication. Again and again to replicate the success of the principles of design, may be the original body of knowledge without any major changes, this stage doubled and widely disseminated innovation.

The third stage: Improve. There are a lot of design flaws and mistakes in past knowledge that needs to be adjusted. The past knowledge will be adjusted so that a unified ecological knowledge in-house becomes more diversified, and individual and collective knowledge are necessary to be adjusted according to the environment in order to improve efficiency.

The fourth stage: Release. This is a total breakdown gradually disappear eventually: the release of a natural component of the combination for the next phase of preparation for the stage. When companies cannot meet the external environment of dramatic changes, companies will have to internally disintegrate based on the release of individual knowledge. However, knowledge is permanently retained in the individuals, when the time is mature, independent knowledge of the individual may reform the new. Overall, start another cycle of knowledge ecosystem. 
The innovation stage is like a new life: the growth and expansion stage shows the material reached the limits of development, and it has entered a stage of improvement. The system is essentially changed, and improved their efficiency, diversity and complexity to reach the limit. But not beyond, it has entered a stage of free, gradually extinction system, which will contain the resources (knowledge) released for the rehabilitation of energy, if the system can go beyond the limits of development, fundamentally changed the structure of its own, and Breakthrough innovation, it can avoid the demise of the system in order to start the next round of the cycle.

\section{The Mechanism of Knowledge Innovation in EKE}

Natural ecosystem's evolution is based on the continuing growth of internal biology, similarly, the evolution of EKE have settled on the knowledge individual's knowledge innovation. When a change happened in the external environment and EKE faced the choice of social pressure, it will inevitably transferred the pressure to the internal individuals. In order to adapt to this choice, knowledge individuals only through continuous innovation to avoid elimination. The way of knowledge innovation similar to evolution of EKE and also can be divided into continuous improvement and breakthrough innovation .

In order to describe the problem better, This article based on previous academic research (Nonaka I. 1994)(Popper K R. 1979) divided the knowledge innovation into three levels: the individual, knowledge and knowledge interactive activities, innovation environmental and purpose, aiming to structure a three-dimensional knowledge innovation mechanism. The individual, knowledge and knowledge interactive activity reflect the specific knowledge innovation process, and the innovation environmental is the room for support, the purpose is the driving force for innovation and results as well as selection criteria (Popper K R. 1979).

The nature of knowledge innovation in EKE is the individual's continuous improving and breakthrough innovating forced by knowledge acquisition mechanism, knowledge-sharing mechanism and knowledge creating mechanism. Knowledge acquirement makes the individual survived, knowledge-sharing to promote the growth of individual, and knowledge creating give birth to the new knowledge and through the final purpose choosing at last, and start over. As the following graph3:

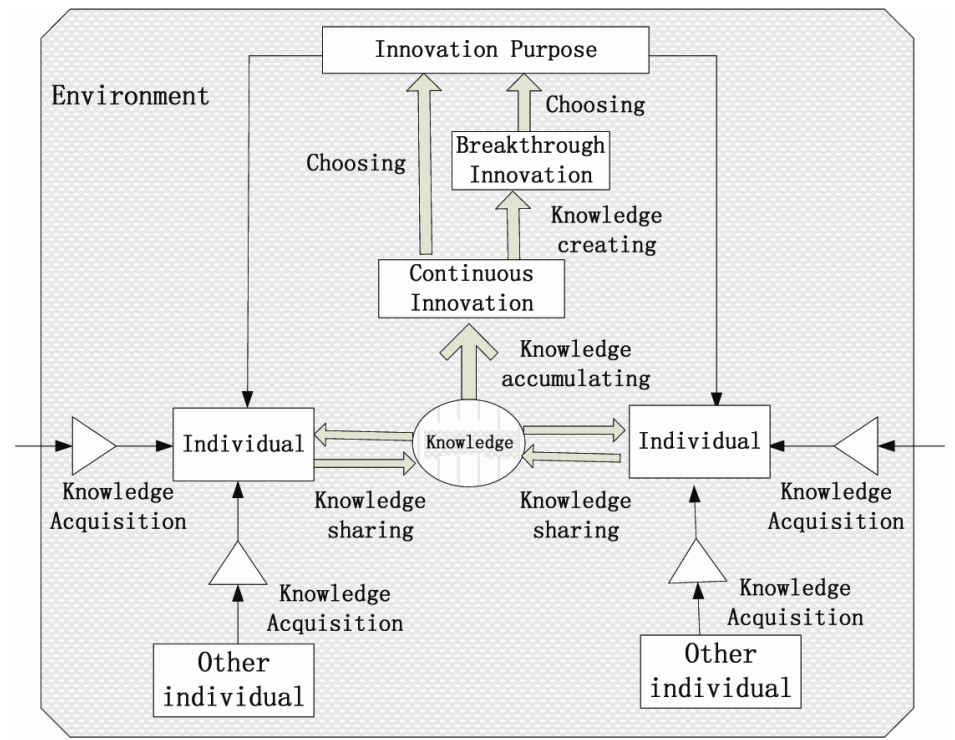

Graph 3. Three-dimensional cross-section graph of knowledge innovation mechanism in EKE

(1) Knowledge Acquisition Mechanism. Access to knowledge is the adaption stage of individual access to survival in the beginning of EKE. In order to promote the establishment and growth of EKE ,individuals will absorb knowledge greedily from external environment in the first time .During the process, some of the outdated and cannot meet the needs of enterprise development knowledge will be removed, but the useful part will be absorbed.

(2)Knowledge Sharing Mechanism. Sharing knowledge is the quantitative changing stage of knowledge innovation. With the steady development of EKE, knowledge between enterprises becoming more and more similar, the knowledge sharing between individuals become the main engine of growth.

(3)Knowledge Creating Mechanism. Knowledge creating is the qualitative changing stage of knowledge innovation. 
Because of the un-imitative, only after individual's further integration, knowledge can be real absorbed, and when the accumulation of knowledge gets to a certain extent, due to the characteristics of people's study and guidelines, it will have the knowledge innovation, creating new knowledge.

\section{Conclusion}

In order to create better products and better to manufacture products, enterprises must continue to carry out innovation. Knowledge Innovation is the ultimate long-term development of business power, knowledge innovation capability of enterprises to maintain a sustained competitive advantage of the most critical factor in the decision. In this paper, through the knowledge of the enterprise eco-innovation process, to make a few points about improving the knowledge ecosystem innovating ideas.

(1) Enterprise Knowledge Ecosystem is an opened system, which in a greater community ecosystem, in order to maintain its sustainable development should be more open to other EKE especially with a number of affluent knowledge organizations (such as universities, research institutions, such as the parent company).

(2)EKE's innovation eventually settled on the i individual growth due to a manual system, it will be able strengthen the knowledge interaction between individuals through some human measures.

(3) From the process of innovation, it can be seen moderate pressure and competition of the outside world is an effective catalyst to EKE and individuals innovating, enterprises should transfer this pressure into engine of knowledge innovation .

(4) Healthy and smooth development of EKE depends on a healthy external environment and also rely on knowledge distribution and coordination of individuals in EKE.

\section{References}

Chen, Yewu. (2000). Foreign Research on knowledge innovation model. Intelligence Magazine, 2000(12).

Iknjiro Nonaka. (1998). The concept of Ba: Building foundation for Knowledge Creation. California Management Review, 1998(3).

Nonaka I. (1994). A Dynamic Theory of Organizational Inowledge Creation. Organizational Science, 1994(1). http://dx.doi.org/10.1287/orsc.5.1.14

Popper K R. (1979). Objective knowledge. Oxford: Clarendon Press.

Sun, Ruyong. (1992). Principles of Animal Ecology. Beijing Normal University Press.

T H Davenport , L Prusak. (1997). Information Ecology. New York :OxfordUniversity,Press.

Tachi Kiuchi, Bill Shireman. (2003). What we learned in the Rainforest. Machinery Industry Press.

Von Krogh Georg. (1998). Care in Knowledge Creation. California Management Review, 1998(3).

Xie, Wangdan. (2004). Review of the Research for the Application of Ecology Theory in the Domain of Economy and Administration. Science and Technology Management Research. 2004(3).

Zhu, Zuping. (2000). Study of KM and its Framework, Scientific management. 2000(1). 